\title{
Comparative Analysis of Two Methods of Calculating the Prescribed Current in a Shunt Active Filtering System
}

\author{
Mihăiță Daniel Constantinescu, Mihaela Popescu, Constantin Vlad Suru \\ University of Craiova, Faculty of Electrical Engineering, Craiova, Romania \\ mconstantinescu@em.ucv.ro, mpopescu@em.ucv.ro, vsuru@em.ucv.ro
}

DOI: 10.52846/AUCEE.2021.1.07

\begin{abstract}
In this paper, the performance of a three-phase shunt active power filter (APF) using the instantaneous power theory (p-q theory) has been compared with that corresponding to the use of the synchronous reference frame (SRF) based method. It is clear that, under balanced and sinusoidal voltage conditions, these two methods gives similar results. The entire system has been modeled using MATLAB-SIMULINK software. The simulation results demonstrate the applicability of both methods for the APF control.
\end{abstract}

Cuvinte cheie: filtru activ de putere, teoria p-q, semnal de referință sincron.

Keywords: Shunt Active Power Filter, $p-q$ Theory, Synchronous Reference Frame.

\section{INTRODUCTION}

Shunt active power filters (SAPFs) are voltage source inverter based static converters, bidirectional in current and voltage, which are connected in parallel with the nonlinear load and controlled so as to meet different compensation objectives (harmonics, reactive power and load unbalance).

Active power filters have many advantages over passive filters, which have established them as a competitive, modern and efficient filtering solution:

- they can reduce the total distortion factor (THD) to very low values, which fall within the limits imposed by regulations (the reduction is greater than 10:1);

- they cannot be overloaded due to the harmonic currents transmitted in the network by other distorting loads;

- the currents to be compensated can be selected;

- harmonic distortion and/or power factor can be compensated, simultaneously or independently (they can also suppress the reactive current, not only harmonic currents);

- the compensation accuracy is higher;

- they do not produce resonances with the power distribution systems;

- they have a great flexibility regarding the location and the connection schemes [1].

The first step in the SAPF control is the generation of the prescribed compensating current based on the sensed supply voltage and load current. There are many methods in the literature used for the calculation of the reference prescribed current, such as those based on the following theories: the instantaneous power (p-q) theory, the synchronous reference frame (SRF), the Conservative Power Theory (CPT), the Currents' Physical Components (CPC), the Fryze-BuchholzDepenbrock (FBD) theory [1]-[13].

Then, the closed-loop control system must be able to handle the accurate tracking of this prescribed current.

In this paper, two methods of generation the prescribed current are analyzed, namely the $\mathrm{p}-\mathrm{q}$ theory based method and synchronous reference frame (SRF) method.

\section{COMPENSATING CURRENT COMPUTATION METHODS}

In this part of study, the control scheme of APF system using p-q theory is discussed and compared with that using synchronous reference frame (SRF) method.

\section{A. The p-q Theory Based Method}

The specificity of the p-q theory lies in the use of socalled instantaneous active and reactive powers ( $p$ and q) in expressing the prescribed compensating current (iF).

$$
\underline{i}_{F}=i_{F \alpha}+j i_{F \beta}=\frac{2}{3} \frac{1}{u_{\alpha}^{2}+u_{\beta}^{2}} \underline{u} \cdot \underline{s}_{F}^{*},
$$

where the SAPF apparent power $(\mathrm{sF})$ is:

$$
\underline{s}_{F}=-p_{\sim}-j q_{\sim} \quad \text { for only the harmonic }
$$
compensation $(\mathrm{p} \sim=\mathrm{p}-\mathrm{P} ; \mathrm{q} \sim=\mathrm{q}-\mathrm{Q})$;

$\underline{s}_{F}=-p_{\sim}-j q$ for the total compensation.

$\mathrm{P}$ and $\mathrm{p} \sim$ are the the average value and the $\mathrm{AC}$ component of the instantaneous active power $\mathrm{p}$.

$\mathrm{Q}$ and $\mathrm{q} \sim$ are the the average value and the $\mathrm{AC}$ component of the instantaneous reactive power $\mathrm{q}$.

The components of voltage and current space vectors ( $u$ and $i)$ in the $(\alpha, \beta)$ stationary reference frame (u $\alpha, u \beta$, $i \alpha, i \beta)$ are used in the expressions of $p$ and $q$ [1]

The Simulink model in Figure 1 corresponds to the objective of total compensation of both current harmonics and reactive power. 


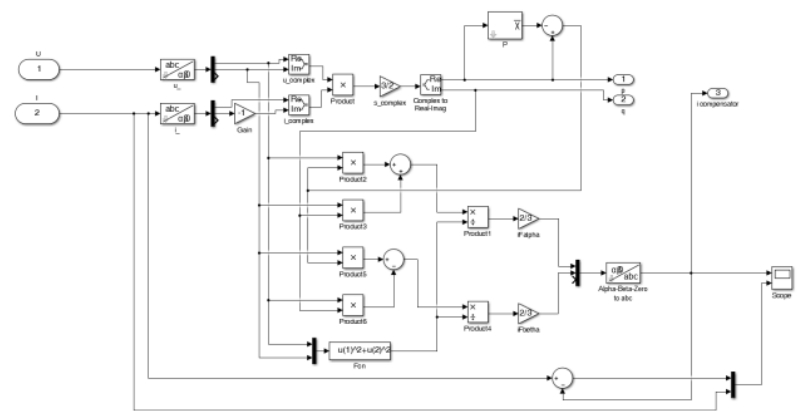

Fig. 1. Simulink model for the prescribed current generation by using the $\mathrm{p}-\mathrm{q}$ theory in the case of total compensation.

The proper prescribed compensating current ensures a sinusoidal supply current after compensation in phase with the supply voltage.

\section{B. The SRF Based Method}

According to SRF method, the three-phase system of real currents is transformed into a two-phase rotating system d-q-0, whose speed is the fundamental pulsation when the identification of the fundamental component of load current is desired (Figure 2) [1]-[4], [14].

$$
\begin{aligned}
{\left[\begin{array}{l}
i_{d} \\
i_{q} \\
i_{0}
\end{array}\right] } & =\frac{2}{3}\left[\begin{array}{ccc}
\cos \theta & \cos (\theta-2 \pi / 3) & \cos (\theta+2 \pi / 3) \\
-\sin \theta & -\sin (\theta-2 \pi / 3) & -\sin (\theta+2 \pi / 3) \\
1 / 2 & 1 / 2 & 1 / 2
\end{array}\right] \cdot\left[\begin{array}{c}
i_{a} \\
i_{b} \\
i_{c}
\end{array}\right]= \\
& =[C] \cdot\left[\begin{array}{l}
i_{a} \\
i_{b} \\
i_{c}
\end{array}\right]
\end{aligned}
$$

$\theta$ is the angular position of the rotating reference system, which is determined by PLL circuits.

The currents obtained in the $(\mathrm{d}, \mathrm{q})$ coordinate system are formed by a direct current component (id-, iq-) and an alternating current component (id , iq ), which can be separated by a low-pass or high-pass filter.

If the rotating system is synchronous with the fundamental component of the current, to separate the compensating current, which corresponds to the alternative components of the current in the (d, q) coordinate system and constitutes the reference current for the active power filter, a high-pass filter is used. Then, the transition to the three-phase system is made by the inverse Park transformation, respectively:

$$
\left\lfloor\begin{array}{l}
i_{F a} \\
i_{F b} \\
i_{F c}
\end{array}\right\rfloor=\left\lfloor\begin{array}{ccc}
\cos \theta & \sin \theta & 1 \\
\cos (\theta-2 \pi / 3) & \sin (\theta-2 \pi / 3) & 1 \\
\cos (\theta+2 \pi / 3) & \sin (\theta+2 \pi / 3) & 1
\end{array}\right\rfloor \cdot\left\lfloor\begin{array}{l}
i_{d \sim} \\
i_{q \sim} \\
i_{0 \sim}
\end{array}\right\rfloor=[D] \cdot\left[\begin{array}{l}
i_{d \sim} \\
i_{q \sim} \\
i_{0 \sim}
\end{array}\right\rfloor(3)
$$

The separation of the fundamental component of the current can also be considered, through the DC components of the current in the rotating system $(\mathrm{d}, \mathrm{q})$ through low-pass filters, followed by the passage in the three-phase system.

The performance of the SRF method are similar, but the $\mathrm{p}-\mathrm{q}$ control method was more effective under transient conditions.

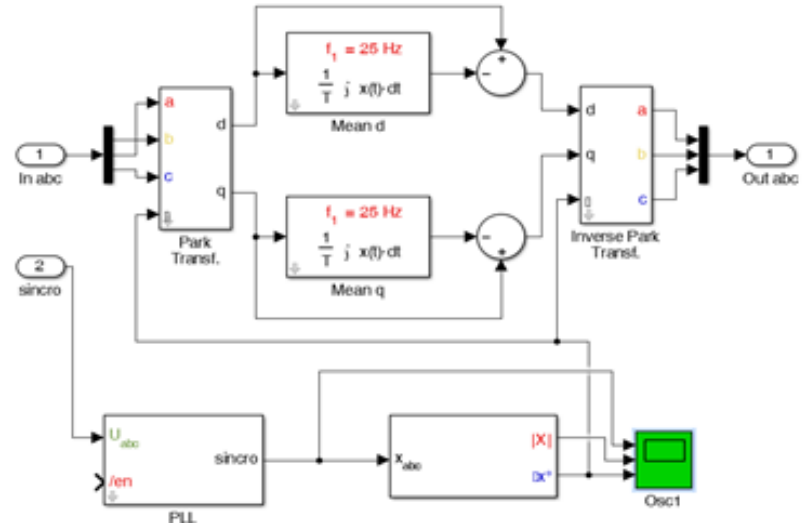

Fig. 2. Simulink model for the prescribed current generation by using the SRF method [2]-[4].

Like all time-frame reference current calculation methods, the SRF method is advantageous in terms of calculation volume, implementation speed, and control complexity compared to the methods in the frequency domain.

In practice, it is not only desired to eliminate a harmonic by active filtering and, therefore, the synchronous rotating system method is applied simultaneously for several harmonics, the reference current for the active filter being the sum of the reference currents on the harmonics.

Problems with the implementation of the synchronous rotating system method are mainly related to the correct detection of the angular position, especially when the three-phase power system is not balanced.

\section{CURRENT CONTROL METHOD}

The role of the active power filter control system is to generate signals for the control of semiconductor devices in the structure of the voltage inverter, so that the current injected into the power supply to follow its reference value. This function is conditioned by the need to control the voltage across the compensation capacitor.

The basic technique of current control by hysteresis, frequently adopted in the control of active filters, involves the generation of control signals for the semiconductor devices in the static converter by comparing the current error with a fixed hysteresis band (Figure 3). In this way, the hysteresis comparator also has the role of current regulator.

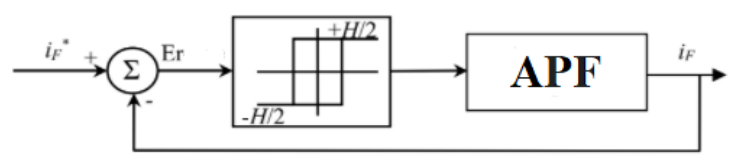

Fig. 3. Block diagram of the hysteresis control technique applied to the direct current control at the filter output.

As long as the error falls within the limits of the hysteresis band, no switching takes place. Switching occurs only when the error exceeds the hysteresis band. Thus, the hysteresis band $(\mathrm{H})$ determines the maximum 
and minimum limits of the current deviation from the reference value (Figure 4 ).

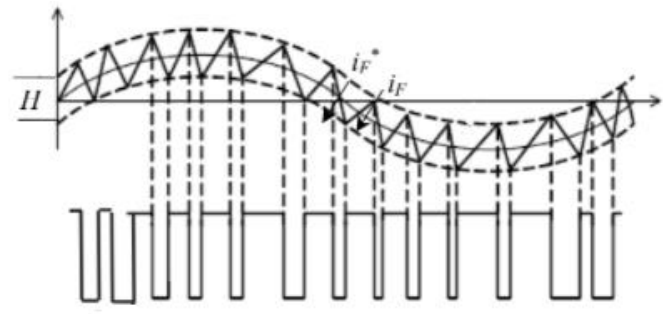

Fig. 4. Generation of the control signal in the case of control with hysteresis.

Therefore, in order to obtain the current compensation with small switching ripples, the value of $\mathrm{H}$ must be reduced, which determines the increase of the switching frequency. In the case of the active power filter, through this instant control, of the "bang-bang" type, the current to be controlled is forced to follow its reference value, without exceeding the tolerance imposed by the hysteresis band.

Although it is simple, robust and allows to obtain good dynamic performances, reasons for which it is frequently adopted in current control structures, the hysteresis control technique has a number of disadvantages, mainly due to the fact that the switching frequency of the converter is variable and is superiorly limited only by the width of the hysteresis band and the dynamics of the system. Thus, the losses in the power semiconductor devices increase, difficulties appear in the design of the interface filter of the active filter and the appearance of unwanted resonances in the network is favored. A negative influence of the filtering performances determined by the interaction of the phase currents was also noticed if the three-phase power system is with isolated zero [1], [5], [6].

The Simulink model of the hysteresis band based control is illustrated in Figure 5 and the generation of the control signals for the IGBTs is shown in Figure 6.

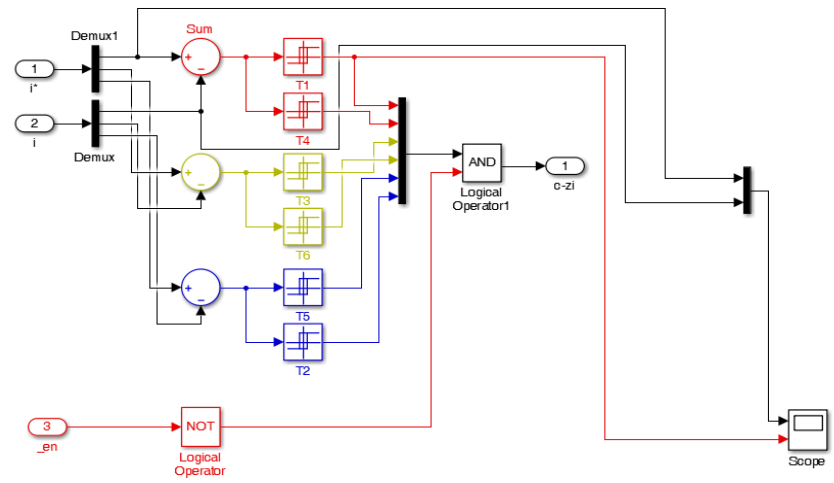

Fig. 5. Simulink model for the basic method of current control by hysteresis.

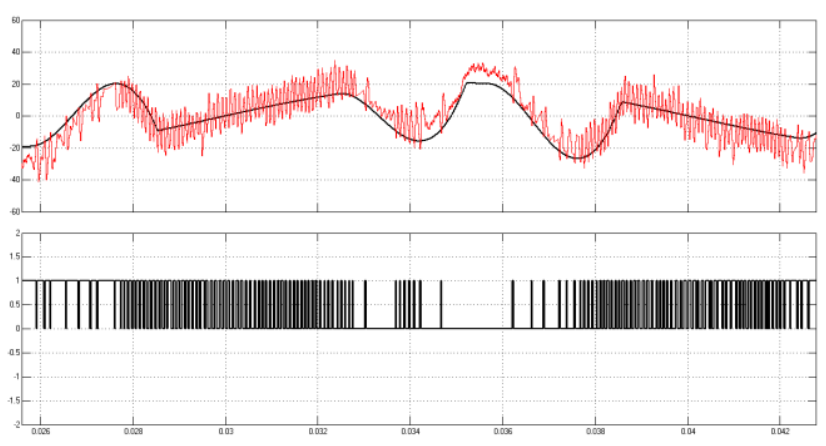

Fig. 6. Generation of the control signal in the case of hysteresis based control - Simulink.

\section{SIMULATION RESULTS}

The study was done by simulation based on specific Simulink models, for both methods of calculating the reference current. It is specified that for the two calculation methods, the load is the same: a three-phase uncontrolled rectifier that feeds a passive load of RC type, which simulates a direct current motor. The current drawn from the power supply by the nonlinear load is shown in Figure 7.

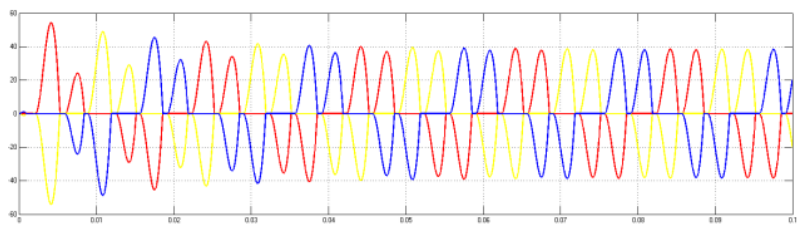

Figure 7 . The waveform of the currents absorbed by the nonlinear load.

The rated values are:

Nominal voltage: $380 \mathrm{~V}$;

Nominal current: $20 \mathrm{~A}$;

Active power: $9.48 \mathrm{~kW}$;

Apparent power: $12.55 \mathrm{~kW}$.

For the current control, the hysteresis based method was used in both simulation systems.

\section{A. The p-q Theory Based Method-Simulink results}

The Simulink model conceived for the whole active filtering system based on the p-q theory based method is shown in Figure 8. All the components are illustrated (power supply, nonlinear load, active power filter with the compensation capacitor on the DC-side and the interface filter of L- type on the AC side, control blocks and calculation blocks). 


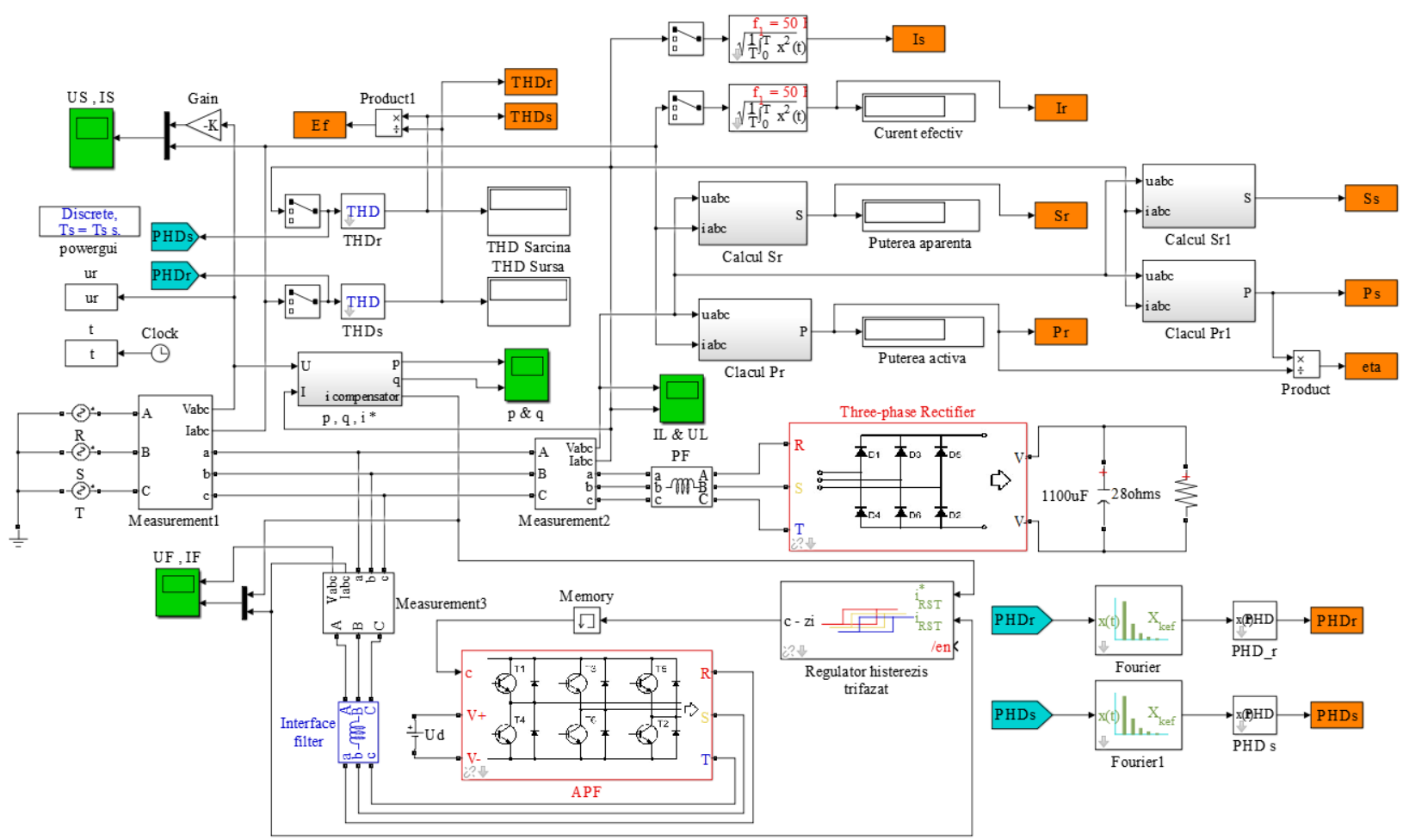

Fig. 8. Simulink model of the active filtering system in case of using the p-q theory based method.

The current waveforms in Figure 9 shows the performance of the active filtering system to perform the total compensation. The supply currents after compensation are very close to the sinusoidal shape, illustrating the switching influence of the inverter, whose effect is not completely eliminated by the inductive interface filter. The remaining distortion factor of the supply current is $5.42 \%$, leading to an active filtering efficiency of about 15.02 (Table I). The currents provided by the voltage source inverter to achieve the compensation are shown in Figure 10.

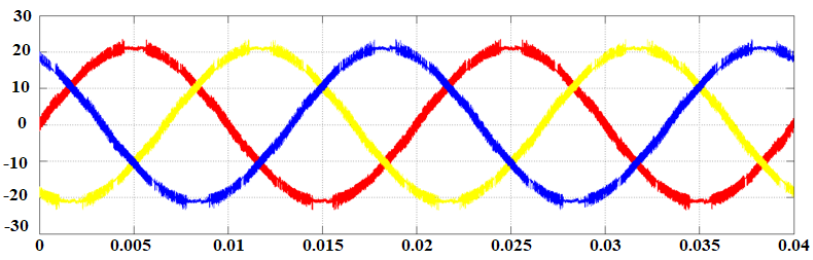

Fig. 9. Current waveforms at the supply side after compensation in case of using the $\mathrm{p}-\mathrm{q}$ theory.

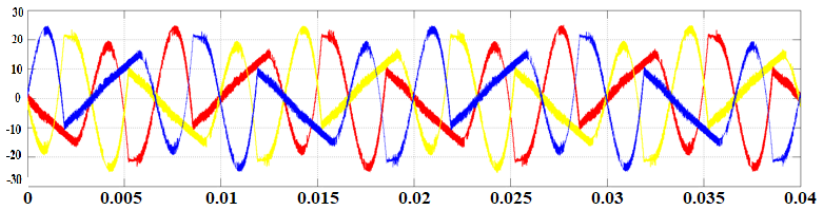

Fig.10. Waveforms of the currents at the inverter output in case of using the $\mathrm{p}-\mathrm{q}$ theory

\section{B. The SRF Based Method-Simulink results}

In the Simulink model of the active filtering system in the case of the SRF based method (Figure 11), the specificity is given by the block "SRF" which provides the reference currents to the current controller.
As with the use of the p-q theory, the supply currents waveforms after compensation (Figure 12) are very close to sinusoids (THD $\approx 5.22 \%$ ). The resulting active filtering efficiency is of about 15.6 (Table I). Figure 13 illustrates the waveforms of the currents at the inverter output in case of using the SRF based method.

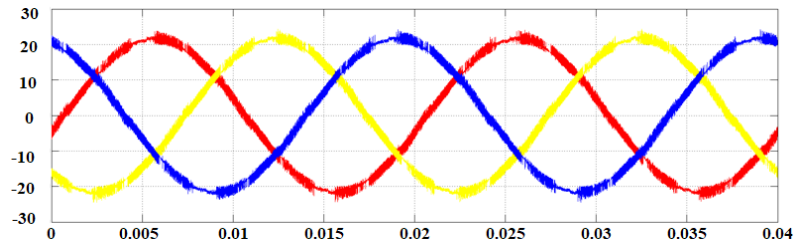

Fig. 12. Current waveforms at the supply side after compensation in case of using the SRF based method.

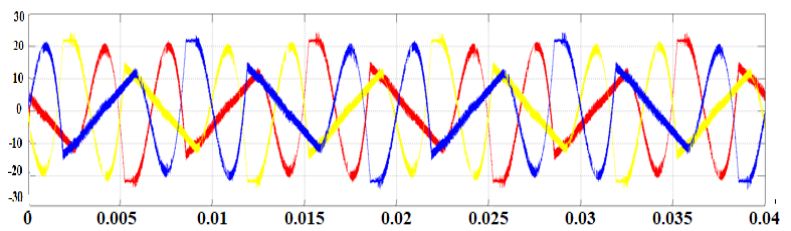

Fig.13. Waveforms of the currents at the inverter output in case of using the SRF based method.

TABLE I.

SUMMARY OF THE NUMERICAL RESULTS

\begin{tabular}{|c|c|c|c|}
\hline \multicolumn{4}{|c|}{ p-q Method } \\
\hline $\begin{array}{c}\text { I (rms) } \\
{[\mathrm{A}]}\end{array}$ & $\begin{array}{c}\text { THD_source } \\
{[\%]}\end{array}$ & $\begin{array}{c}\text { THD_load } \\
{[\%]}\end{array}$ & $\begin{array}{c}\text { Active } \\
\text { filtering } \\
\text { efficiency }\end{array}$ \\
\hline 19.02 & 5.42 & 81.41 & 15.0202 \\
\hline
\end{tabular}




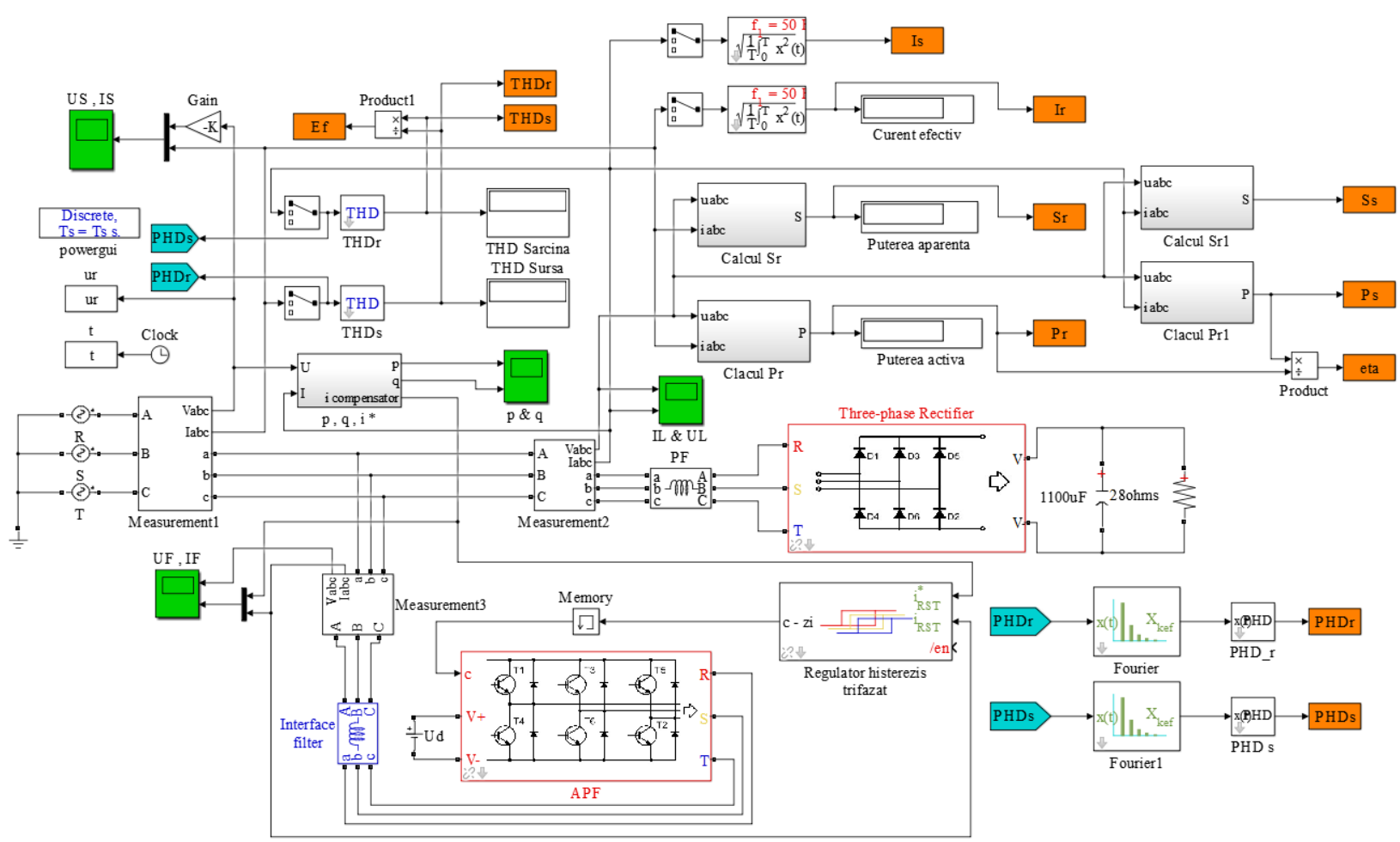

Fig.11. Simulink model of the active filtering system in case of using the SRF based method.

A summary of the numerical results obtained by simulation is presented in Table I and Table II. As shown, the THD values of the currents after compensation are very close to the value of $5 \%$ recommended by Std. IEEE 519 [15].

TABLE II.

SUMMARY OF THE NUMERICAL RESULTS

\begin{tabular}{|c|c|c|c|}
\hline \multicolumn{4}{|c|}{ SRF Method } \\
\hline $\begin{array}{c}\text { I (rms) } \\
{[\mathrm{A}]}\end{array}$ & $\begin{array}{c}\text { THD_source } \\
{[\%]}\end{array}$ & $\begin{array}{c}\text { THD_load } \\
{[\%]}\end{array}$ & $\begin{array}{c}\text { Active } \\
\text { filtering } \\
\text { efficiency }\end{array}$ \\
\hline 19.02 & 5.22 & 81.41 & 15.5957 \\
\hline
\end{tabular}

\section{CONCLUSION}

Two methods for the reference current generation used in the control of a three-phase shunt active power filter, namely the $p-q$ theory based method and the SRF based method, were investigated in this paper.

Under balanced and sinusoidal supply voltages these two methods gives similar results for total compensation.

Under nonideal voltage conditions, the synchronous reference frame method leads to better results. However, the p-q method allows the compensation of only the current harmonics, or of the reactive power, or the total compensation, being more flexible.

The SRF method is advantageous in terms of the volume of calculations, the execution speed associated with the implementation and the complexity of the control.

Both methods are frequently adopted in the control of active power filters.

\section{ACKNOWLEDGMENT}

This work was supported by the grant POCU380/6/13/123990, co-financed by the European Social Fund within the Sectorial Operational Program Human Capital 2014 - 2020.

Contribution of authors:

Mihăiță Daniel Constantinescu - 60\%

Mihaela Popescu - 20\%

Vlad Constantin Suru- 20\%

Received on August 08,2021

Editorial Approval on November 29, 2021

\section{REFERENCES}

[1] Bitoleanu, A., Popescu, Mihaela, Suru V.C., Filtre active de putere - Fundamente si aplicatii, Bucuresti, Matrix, 2021.

[2] Popescu, Mihaela, Preda, Alexandra. Suru, V., "Synchronous reference frame method applied in the indirect current control for active DC traction substation", Athens: ATINER'S Conference Paper Series, No: TRA2015-1552, 2015, pp. 1-6, 8-11 June 2015.

[3] Suru, C.V., Patrascu, Alexandra, Linca M.. "The synchronous fundamental $\mathrm{dq}$ frame theory application for the active filtering", Annals of the University of Craiova, Electrical Engineering series, No. 38, pp. 92-97, 2014.

[4] Suru, C.V., Patrascu, Alexandra, Linca M., "The synchronous fundamental dq frame theory implementation and adaptation for the active filtering", $12^{\text {th }}$ International Conference on Applied and Theoretical Electricity, Craiova, Romania, 23-25 October 2014.

[5] Asiminoaei, L., Blaabjerg, F.. Hansen, S., "Detection is key. Harmonic detection methods for active power filter 
applications", IEEE Industry Applications Magazine, Vol. 13, Issue 4, pp. 22-33, July/Aug. 2007.

[6] Asiminoaei, L., Blaabjerg. F., Hansen, S.. "Evaluation of harmonic detection methods for active power filter applications", Applied Power Electronics Conference and Exposition, pp. 635-641, 2005.

[7] Pătrașcu, Alexandra, Popescu, Mihaela, Suru, V.; "The conservative power theory and the active Filtering", Bulletin AGIR No. 4, pp. 179-182, 2012.

[8] Suru, V., Pătraşcu, Alexandra, Popescu, Mihaela, Bitoleanu, A., "Conservative, power theory application in shunt active power filtering under asymmetric voltage", The $14^{\text {th }}$ International Conference on Optimization of Electrical and Electronic Equipment (OPTIM 2014), , Braşov Cheile Grădiştei, Romania, pp. 647 - 654, 22-24 May 2014.

[9] Popescu, Mihaela, Bitoleanu, A., Suru, V., "Currents' Physical Components theory implementation in shunt active power filtering for unbalanced loads", $11^{\text {th }}$ Conference-Seminar International School on Nonsinusoidal Currents and Compensation (ISNCC), , Zielona Gora, Poland, pp.1-6, 20-21 June 2013.

[10] Popescu, Mihaela, Bitoleanu, A., Dobriceanu, M., "FBD-based control in active dc-traction substations", $13^{\text {th }}$ International Conference on Applied and Theoretical Electricity (ICATE), Craiova, Romania, Oct. 6-8, 2016.
[11] Popescu, Mihaela, Pătrașcu, Alexandra, Dobriceanu, M. "Application of generalized instantaneous reactive/non-active power theories in the control of shunt active power line conditioners: Practical evaluation under nonideal voltage and unbalanced load", Book Chapter: Nonlinear Dynamics of Electronic Systems, Series: Communications in Computer and Information Science, Vol. 438, pp. 125-133, 2014.

[12] Popescu, Mihaela, Bitoleanu, A., Dobriceanu, M., Suru, V., "Optimum control strategy of three-phase shunt active filter system", Proceedings of World Academy of Science, Engineering and Technology, Vol. 58, pp. 245-250, October 2009.

[13] Popescu, Mihaela, Bitoleanu, A., Suru, V., Patrascu, Alexandra, "High performance shunt active power filter", $7^{\text {th }}$ International Symposium on Advanced Topics in Electrical Engineering (ATEE), Bucharest, pp. 1-6, 12-14 May 2011.

[14] Teodorescu, R., Liserre, M.. Rodríguez, P., Appendix A: Space vector transformations of three-phase systems, Grid Converters for Photovoltaic and Wind Power Systems, 19 Dec. 2010.

[15] Hoevenaars, T., LeDoux, K., Colosino, M., Interpreting IEEE STD 519 and meeting its harmonic limits in VFD applications, Petroleum and Chemical Industry Conference, pp. 145-150, 2003. 